\title{
Structure and Magnetic Properties of Zn2+- Doped Cobalt Ferrite Nanoparticles Synthesized by Sol-gel Spontaneous Combustion
}

\author{
Ratvindra Celange \\ Department of Physics, Shri. Madhavrao Patil Mahavidyalaya, Murum, Osmanabad, M.S., 413605, India, \\ ravikiran.alange@gmail.com
}

\begin{abstract}
Zinc $\left(\mathrm{Zn}^{2+}\right)$ doped spinel cobalt ferrites nanoparticles having composition $\left(\mathrm{Zn}_{x} \mathrm{Co}_{1-x} \mathrm{Fe}_{2} \mathrm{O}_{4}\right.$ where $x=0.2$, 0.4) were synthesized by sol-gel auto combustion method. The structural and magnetic properties were characterized via X-ray diffraction (XRD) technique and Pulse field hysteresis loop tracer. The average crystallite size (D) was found to decrease from $32.15 \mathrm{~nm}$ to $24.31 \mathrm{~nm}$ with increasing the $\mathrm{Zn}^{2+}$. Magnetization field loops reveal ferromagnetic behavior, lower hysteresis loop observed for higher Zn content. The magnetic properties are remarkably influenced with Zn doping; saturation magnetization (Ms) decreases then increases while both coercivity $(\mathrm{HC})$ and remanent magnetization $(\mathrm{Mr})$ decrease with increase in $\mathrm{Zn}^{2+}$ content, which was associated with preferential site occupancy and the change in average crystallite size.
\end{abstract}

Keywords: XRD, Magnetization, Spinel ferrite, nanoparticles

\section{Introduction}

Spinel ferrite nanoparticles have general formula of $\mathrm{MFe}_{2} \mathrm{O}_{4}$, where $\mathrm{M}$ is a metal cation with charge such as $\mathrm{Mn}$, $\mathrm{Fe}, \mathrm{Cu}, \mathrm{Ni}$ and $\mathrm{Zn}$. These nanoparticles have unique magnetic and electrical properties and thus have been utilized in many applications such as, magnetic recording and sensing, information storage, catalysis, gas sensors, battery applications [1-3]. This is because of various interesting properties possessed by the materials, e.g., strong anisotropy, high saturation, coercivity, etc. [4]. The magnetic properties of the $\mathrm{CoFe}_{2} \mathrm{O}_{4}$ are greatly affected by the size of the particles, by cation substitution and distribution [5]. $\mathrm{ZnFe}_{2} \mathrm{O}_{4}$ is a normal spinel with all the $\mathrm{Fe}^{3+}$ ions in the sites and all the $\mathrm{Zn}^{2+}$ ions in the (A) sites, whereas $\mathrm{CoFe}_{2} \mathrm{O}_{4}$ has an inverse spinel structure with the $\mathrm{Co}^{2+}$ ions mainly in the sites and $\mathrm{Fe}^{3+}$ ions distributed almost equally between the (A) and the sites[6]. However, $\mathrm{ZnFe}_{2} \mathrm{O}_{4}$ with an extreme case has an inverse spinel structure. $\mathrm{Zn}^{2+}$ substitution in $\mathrm{CoFe}_{2} \mathrm{O}_{4}$ may have some distorted spinel structures depending upon the concentration of cations. Therefore, $\mathrm{CoZnFe}_{2} \mathrm{O}_{4}$ has a mixed spinel type of structure. It is known that zinc ions $\left(\mathrm{Zn}^{2+}\right)$ with diamagnetic nature are known for achieving good control over magnetic parameters in developing technologically important materials [7-9]. Substitution of magnetic $\left(\mathrm{Co}^{2+}\right)$ by a nonmagnetic $\left(\mathrm{Zn}^{2+}\right)$ cation in spinel ferrite phase may induce important changes in their structural, optical, magnetic, and others properties, due to the distribution of cations in between the available A and B sites. A lot of work has been reported in the literature about different types of nonmagnetic and magnetic ions doped Co-ferrites synthesized by various methods. [10-15]. In this work, we investigate the magnetic and structural properties of $\mathrm{Zn}^{2+}$ ions substituted cobalt ferrite, $\mathrm{Zn}_{\mathrm{x}} \mathrm{Co}_{1-\mathrm{x}} \mathrm{Fe}_{2} \mathrm{O}_{4}$ ( $\mathrm{x}=0$ 0, 0.2 and 0.4 ) synthesized by the sol gel auto-combustion method. The substitution of non-magnetic $\mathrm{Zn}^{2+}$ ion is expected to modify structural and magnetic properties by altering the cation distribution between the two crystallographic (A) and [B] sites.

\section{Experimental}

The nanocrystalline zinc ions substituted cobalt ferrite nanoparticles $\mathrm{Co}_{1-\mathrm{x}} \mathrm{Zn}_{\mathrm{x}} \mathrm{Fe}_{2} \mathrm{O} 4(\mathrm{x}=0.0-0.4)$ were synthesized by the sol auto combustion method. For the preparation of $\mathrm{Co}_{1-\mathrm{x}} \mathrm{Zn}_{\mathrm{x}} \mathrm{Fe}_{2} \mathrm{O} 4(\mathrm{x}=0.0,0.2,0.4)$ nanoparticles through sol gel auto combustion method. cobalt, zinc, and iron nitrates were taken in stoichiometric proportions and then dissolved separately in de-ionized water at constant heating at 60-80 ${ }^{\circ} \mathrm{C}$ under continuous stirring. The glycine was used as chelating agent for combustion. The glycine solution was added separately to cobalt nitrate, zinc nitrate and iron nitrate solutions, with continuously heating and stirring; to obtain a transparent brown color glossy gel. The molar ratio of nitrates to glycine was taken according to propellent chemistry. Heating was continued at above $1000 \mathrm{C}$, the gel was then swelled and ignited with evolution of large amount of gaseous product, resulting the desired ferrite in the form of foamy powder. The obtained powders were then finally calcined at $700{ }^{\circ} \mathrm{C}$ for $5 \mathrm{~h}$.

\section{Characterization}

X-ray diffraction (XRD) measurements were recorded with Ultima IV, Rigaku Corporation, Japan. by using $\mathrm{Cu}-\mathrm{K} \alpha$ radiation $(\lambda=1.5418 \AA)$. The XRD patterns were recorded at room temperature in the $2 \theta$ range of $200-800$ with a step size of 0.02 and a speed of $0.5 / \mathrm{min} . \mathrm{M}-\mathrm{H}$ of all samples was studied with help of pulse field hysteresis loop tracer (Magneta Ltd.) technique at room temperature.

\section{Results and Discussions}

\subsection{X-ray diffraction analysis}

The X-ray diffraction patterns of the $\mathrm{Co}_{1-\mathrm{x}} \mathrm{Zn}_{\mathrm{x}} \mathrm{Fe}_{2} \mathrm{O}_{4}$ spinel ferrite nanoparticles with $\mathrm{x}=0.0,0.2,0.4$ are shown in Fig. 1.0. From the X-Ray diffraction analysis data, it is found that all diffraction peaks very well match with reported in 
literature [16] and (ICDD: 01-072-6799). The peak broadness can be attributed to the nanocrystalline nature of the prepared samples. The intensity of the XRD peaks is found to decrease while the peak broadening increases with increasing $\mathrm{Zn}^{2+}$ doping concentration. The lattice constant, crystallite size and X-ray density was calculated from the obtained XRD data and all these parameters calculated using the relation $[17,18]$ and is tabulated in Table 1 .

Table 1: Lattice constant, crystallite size and $\mathrm{X}$-ray density of $\mathrm{Co}_{1-\mathrm{x}} \mathrm{Zn}_{\mathrm{x}} \mathrm{Fe}_{2} \mathrm{O}_{4}$ nanoparticles

\begin{tabular}{|c|c|c|c|}
\hline $\begin{array}{c}\text { conc } \\
\text { ' } \mathrm{x} \text { ' }\end{array}$ & $\begin{array}{c}\text { Lattice parameter } \\
\text { 'a' }(\hat{\AA})\end{array}$ & $\begin{array}{c}\text { Crystallite size } \\
(\mathrm{nm})\end{array}$ & $\begin{array}{c}\text { X-ray density } \\
\left(\mathrm{gm} / \mathrm{cm}^{3}\right)\end{array}$ \\
\hline 0.0 & 8.372 & 32.15 & 5.610 \\
\hline 0.2 & 8.378 & 28.02 & 5.774 \\
\hline 0.4 & 8.487 & 24.31 & 5.875 \\
\hline
\end{tabular}

The lattice parameter is found to increase from $8.372 \AA$ to $8.487 \AA$ with increasing $\mathrm{Zn}^{2+}$ doping. The increase of lattice parameter with $\mathrm{Zn}^{2+}$ doping concentration can be explained on the basis of the difference in ionic radii of $\mathrm{Zn}^{2+}$ and $\mathrm{Co}^{2+}$. The smaller ionic radius of $\mathrm{Co}^{2+}(0.58 \AA)$ was replaced by the larger ionic radius of $\mathrm{Zn}^{2+}(0.6 \AA)$ so the lattice parameter increased due to the expansion of the unit cell [19]. All the peaks in the diffraction pattern have been indexed and Cohen's method was used for the refinement of the lattice parameter [20]. The crystallite was calculated by using Scherrer's equation. The crystallite size was found in the rage $24.32 \mathrm{~nm}$ to $32.15 \mathrm{~nm}$. Crystallite size decreases with the increase in $\mathrm{Zn}^{2+}$ substitution.

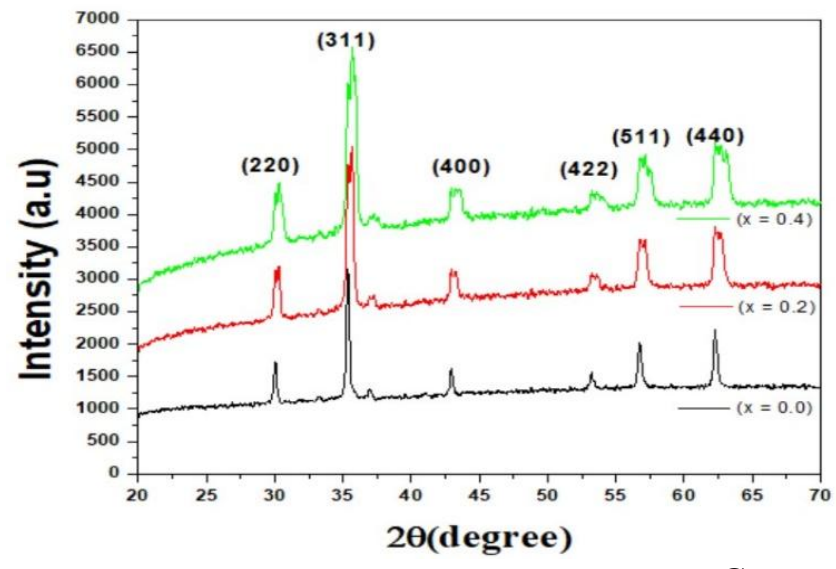

Figure 1: The $\mathrm{X}$-ray diffraction patterns of the $\mathrm{Co}_{1}$ ${ }_{x} \mathrm{Zn}_{\mathrm{x}} \mathrm{Fe}_{2} \mathrm{O} 4$ as function of $\mathrm{Zn}^{2+}$ content

The reduction in particles size is may be due to the mechanically induced contraction in $\mathrm{Co}-\mathrm{Zn}$ ferrite due to the deformation of $\mathrm{Fe}^{2+}-\mathrm{O}^{2}-\mathrm{Fe}^{3+}$. The X-ray density increases with increase in $\mathrm{Zn}^{2+}$ ions. This may be due to the larger atomic weight of the $\mathrm{Zn}^{2+}$ ions as compared to that of $\mathrm{Co}^{2+}$ ions.

\subsection{Magnetic Properties}

Magnetic hysteresis (M-H) loops of the prepared nanoparticles recorded at $300 \mathrm{~K}$ are shown in Fig. 2. From hysteresis loop, it is observed that, the $\mathrm{CoFe}_{2} \mathrm{O}_{4}$ shows a ferromagnetic behavior with a large hysteresis loop. Doping with $\mathrm{Zn}$ ions reveals also a ferromagnetic behavior while induces important modifications in the magnetic properties; the hysteresis loop decreases drastically with $\mathrm{Zn}$ content.
Magnetic parameters such as saturation magnetization (Ms), remanence magnetization $(\mathrm{Mr})$ and coercivity (Hc), magnetic moment $(\eta \mathrm{B})$, were calculated for all samples at room temperatures and are listed in Table 2.

Table 2: Saturation magnetization (Ms), remanence magnetization $(\mathrm{Mr})$, coercivity $(\mathrm{Hc})$, remanent ratio $(\mathrm{R})$, Calculated (nB) and Magnetic moment $\mathrm{Co}_{1-\mathrm{x}} \mathrm{Zn}_{\mathrm{x}} \mathrm{Fe}_{2} \mathrm{O} 4$ nanoparticles

\begin{tabular}{|c|c|c|c|c|c|}
\hline \multirow{2}{*}{ Conc'x' } & $\mathrm{MS}$ & $\mathrm{Mr}$ & $\mathrm{HC}$ & \multirow{2}{*}{$\mathrm{Mr} / \mathrm{MS}$} & $\begin{array}{c}\mathrm{nB} \\
(\mu \mathrm{B})\end{array}$ \\
\cline { 2 - 4 } & $(\mathrm{emu} / \mathrm{g})$ & $(\mathrm{emu} / \mathrm{g})$ & $(\mathrm{Oe})$ & & 3.45 \\
\hline 0.0 & 84.15 & 74.56 & 1122 & 0.907 & 3.58 \\
\hline 0.2 & 82.66 & 36.00 & 496 & 0.425 & 3.58 \\
\hline 0.4 & 98.12 & 23.00 & 186 & 0.234 & 4.16 \\
\hline
\end{tabular}

It is observed from M-H loop and tabulated data of table 2, saturation magnetization increases with increase in $\mathrm{Zn}$ content. This could be due to $\mathrm{Zn}^{2+}$ (with zero magnetic moment) replace ion on the tetrahedral (A) sites, causing the decrease of magnetic moment in the sub-lattice MA, resulting in the increase of total magnetic. It is also observed that the remanence magnetization decreases with increase in zinc content $x$. The decrease in remanence magnetization values can be attributed to the substitution of nonmagnetic zinc ions in cobalt ferrite [21]. M-H plot shows that the all samples show high values of coercivity confirming the nanocrystalline nature. Further, it can be observed that the coercivity decreases with increase in substitution of zinc content $\mathrm{x}$.

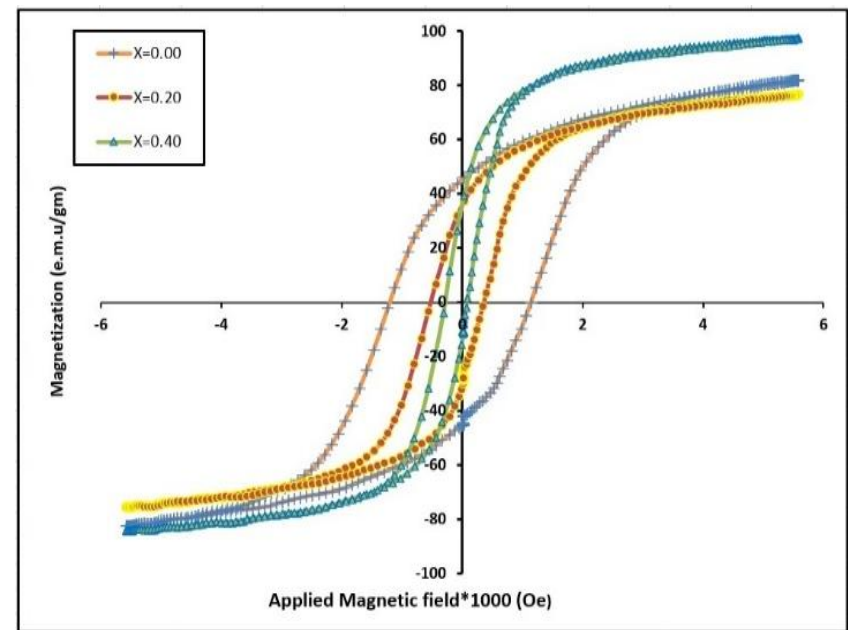

Figure 2: $\mathrm{M}-\mathrm{H}$ curves of the $\mathrm{Co}_{1-\mathrm{x}} \mathrm{Zn}_{\mathrm{x}} \mathrm{Fe}_{2} \mathrm{O}_{4}$ nanoparticles recorded at $300 \mathrm{~K}$.

The decrease in coercivity values can be attributed to the substitution of nonmagnetic zinc ions in cobalt ferrite. Table 2 shows that the values of all magnetic parameters decrease as a function of substitution of zinc content $x$. It may be due to the fact that nonmagnetic zinc replaces magnetic $\mathrm{Co}^{2+}$ ions. The A-B magnetic interaction decreases due to substitution of zinc, as a result of which the magnetic properties decrease as a function of zinc content $x$ [22].

\section{Conclusion}

Zn-doped cobalt-ferrite nanoparticles, with nominal composition $\mathrm{Co}_{1-\mathrm{x}} \mathrm{Zn}_{\mathrm{x}} \mathrm{Fe}_{2} \mathrm{O} 4$ ( $\mathrm{x}=0.0,0.2$, and 0.4), were successfully synthesized by sol gel auto-combustion 
technique. The analysis of XRD patterns reveals the formation of single-phase cubic spinel structure. The saturation magnetization increases with increase in $\mathrm{Zn}$ content while remanence magnetization and coercivity decrease as a function of substitution of zinc content $x$. It may be due to the fact that nonmagnetic zinc replaces magnetic $\mathrm{Co}^{2+}$ ions.

\section{Acknowledgement}

Author is thankful to scientific instrumentation center, Punyashlok Ahilyadevi Holkar University, for provide Xray diffraction data, and also thankful to SMPM,college Murum for provide magnetization data and lab facilities.

\section{References}

[1] M. Amiri, K. Eskandari, M. Salavati-Niasari, magnetically retrievable ferrite nanoparticles in the catalysis application, Advances in colloid and interface science, 271 (2019) 101982.

[2] R. Ranga, A. Kumar, P. Kumari, P. Singh, V. Madaan, K. Kumar, Ferrite application as an electrochemical sensor: A review, Materials Characterization, (2021) 111269.

[3] T.D. Dongale, S.S. Khot, A.A. Patil, S.V. Wagh, P.B. Patil, D.P. Dubal, T.G. Kim, Bifunctional nanoparticulated nickel ferrite thin films: Resistive memory and aqueous battery applications, Materials \& Design, 201 (2021) 109493.

[4] Y. Kitamoto, S. Kantake, F. Shirasaki, M. Abe, M. Naoe, Co ferrite films with excellent perpendicular magnetic anisotropy and high coercivity deposited at low temperature, Journal of Applied physics, 85 (1999) 4708-4710.

[5] M. Artus, L.B. Tahar, F. Herbst, L. Smiri, F. Villain, N. Yaacoub, J.-M. Grenèche, S. Ammar, F. Fiévet, Size-dependent magnetic properties of $\mathrm{CoFe} 2 \mathrm{O} 4$ nanoparticles prepared in polyol, Journal of Physics: Condensed Matter, 23 (2011) 506001.

[6] J. Yao, X. Li, Y. Li, S. Le, Density functional theory investigations on the structure and electronic properties of normal spinel $\mathrm{ZnFe} 2 \mathrm{O} 4$, Integrated Ferroelectrics, 145 (2013) 17-23.

[7] M.A. Gabal, Y. Al Angari, Effect of diamagnetic substitution on the structural, magnetic and electrical properties of $\mathrm{NiFe} 2 \mathrm{O} 4$, Materials Chemistry and Physics, 115 (2009) 578-584.

[8] B. Świạtek-Tran, H. Kołodziej, V. Tran, Zn (C3H3N2) 2: a novel diamagnetic insulator, Journal of Solid State Chemistry, 177 (2004) 1011-1016.

[9] A. Upadhyay, S.K. Singh, C. Das, R. Mondol, S.K. Langley, K.S. Murray, G. Rajaraman, M. Shanmugam, Enhancing the effective energy barrier of a Dy (iii) SMM using a bridged diamagnetic $\mathrm{Zn}$ (ii) ion, Chemical Communications, 50 (2014) 8838-8841.

[10] H. Mund, B. Ahuja, Structural and magnetic properties of $\mathrm{Mg}$ doped cobalt ferrite nano particles prepared by sol-gel method, Materials Research Bulletin, 85 (2017) 228-233.

[11] K.J. Sankaran, S. Suman, A. Sahaw, U. Balaji, R. Sakthivel, Improved LPG sensing properties of nickel doped cobalt ferrites derived from metallurgical wastes, Journal of Magnetism and Magnetic Materials, (2021) 168231.

[12] P.A. Vinosha, A. Manikandan, A.S.J. Ceicilia, A. Dinesh, G.F. Nirmala, A.C. Preetha, Y. Slimani, M. Almessiere, A. Baykal, B. Xavier, Review on recent advances of zinc substituted cobalt ferrite nanoparticles: Synthesis characterization and diverse applications, Ceramics International, (2021).

[13] S.K. Gore, S.S. Jadhav, V.V. Jadhav, S. Patange, M. Naushad, R.S. Mane, K.H. Kim, The structural and magnetic properties of dual phase cobalt ferrite, Scientific reports, 7 (2017) 1-9.

[14] M. Ahsan, M. Islam, F. Khan, Tunability of ac conductivity in manganese doped cobalt ferrite nanoparticles, Results in Physics, 21 (2021) 103782.

[15] L. Zhao, H. Zhang, Y. Xing, S. Song, S. Yu, W. Shi, X. Guo, J. Yang, Y. Lei, F. Cao, Studies on the magnetism of cobalt ferrite nanocrystals synthesized by hydrothermal method, Journal of Solid State Chemistry, 181 (2008) 245-252.

[16] N. Somaiah, T.V. Jayaraman, P. Joy, D. Das, Magnetic and magnetoelastic properties of $\mathrm{Zn}$-doped cobalt-ferrites- $\mathrm{CoFe} 2-\mathrm{xZnxO} 4(\mathrm{x}=0,0.1,0.2$, and 0.3 ), Journal of Magnetism and Magnetic Materials, 324 (2012) 2286-2291.

[17] B.D. Cullity, Elements of X-ray Diffraction, AddisonWesley Publishing, 1956.

[18] V. Vinayak, P.P. Khirade, S.D. Birajdar, P. Gaikwad, N. Shinde, K. Jadhav, Low temperature synthesis of magnesium doped cobalt ferrite nanoparticles and their structural properties, International Advanced Research Journal in Science, Engineering and Technology, 2 (2015).

[19] R.t. Shannon, C. Prewitt, Revised values of effective ionic radii, Acta Crystallographica Section B: Structural Crystallography and Crystal Chemistry, 26 (1970) 1046-1048.

[20] J. Langford, The accuracy of cell dimensions determined by Cohen's method of least squares and the systematic indexing of powder data, Journal of Applied Crystallography, 6 (1973) 190-196.

[21] D.S. Nikam, S.V. Jadhav, V.M. Khot, R. Bohara, C.K. Hong, S.S. Mali, S. Pawar, Cation distribution, structural, morphological and magnetic properties of Co $1-$ x Zn x Fe 2 O 4 ( $\mathrm{x}=0-1)$ nanoparticles, RSC Advances, 5 (2015) 2338-2345.

[22] S.S. Jadhav, S.E. Shirsath, S.M. Patange, K. Jadhav, Effect of $\mathrm{Zn}$ substitution on magnetic properties of nanocrystalline cobalt ferrite, Journal of Applied Physics, 108 (2010) 093920. 